\title{
Stableness MeASUREMENT MODEL: A Mathematical ApProach FOr Measuring THE STABILITY OF HANDHELd APPLICATION USAGE
}

\author{
Amalina Farhi Ahmad Fadzlah ${ }^{1}$ \\ ${ }^{1}$ Department of Computer Science, Faculty of Defence Science and Technology, \\ Universiti Pertahanan Nasional Malaysia, 57000 Kuala Lumpur, Malaysia \\ amalina.farhi@upnm.edu.my
}

\begin{abstract}
This study is designed to develop a mathematical model for measuring the stability of handheld application usage namely Stableness Measurement Model (SMM). This model outlined a series of formulas based on the total number of eleven stability measures (i.e. eight stability metrics and three stability attributes) which are identified as having associated and contributed towards measuring the stability of handheld application usage. This model is valuable as an alternative evaluation technique to be used for measuring and ensuring the stability of handheld application usage.
\end{abstract}

\section{KEYWORDS}

Stability, model, measure, handheld, application

\section{INTRODUCTION}

Stability is one of the most fundamental and important of all usable and useful software characteristics. The term stability means making the condition of software of being resistant to change of position or condition with which not easily moved or disturbed [1]. Other definition described stability as quality or attribute of being firm and steadfast to software that bare on the provision of right or agreed results or effects with continuous function well in an acceptable period [2]. In this paper, the term stability in the perspective of useful and usable can be defined as the degree to which making the condition of software of being stable or steady in relation to correct or complete as well as effort and time, that reflects the real world object or event being described, based on the users' needs and requirements. The fewer failures and times taken to complete tasks that are observed the more stable an application is.

Stability normally plays an important factor for all software quality elements. Over the past few decades, several researches for assessing and evaluating stability of software have been mentioned. The international standard, ISO/IEC 9126 [2], described stability as quality sub attribute to software that bare on the provision of the ease with which a product can be maintained in order to improve reliability. In the other hand, stability correlates with the metrics which measure attributes of the software that indicate about the risk of unexpected effects as a result of modification [3][4][5]. Some researchers also classify stability as an essential characteristic for evaluating and assessing the usability of software [6][7][8][9]. Within the domain of handheld software, several researchers have proposed to explore the concept of stability [10][11][12][13].

DOI : 10.5121/ijsea.2013.4504 


\section{MATERIALS AND METHODS}

This study outlined three main questions: 1) what stability measures are really important; 2) what is the rank of each stability measure; and 3 ) what is the weight of each stability measure, towards measuring the stability of handheld application usage. In order to answer these questions, a questionnaire survey, namely Investigating Stability Measures for Handheld Application Usage was conducted among handheld device users and a total number of two hundred nineteen respondents responded.

These stability measures were classified into three hierarchical levels of metrics, attributes and criterions. Metrics are described as the lowest hierarchy level. The main objective of the metrics is to identify measurable data for the purpose of measuring the stability of handheld application usages. The middle hierarchy level is described as attributes, whereas the highest is described as criterion (i.e. stability of handheld application usage). This hierarchy which brings together three different stability levels of metrics, attributes and criterion is as detailed below (Table 1).

Table 1 . Stability hierarchy level

\begin{tabular}{|l|l|}
\hline Hierarchy & Description \\
\hline Metric & $\begin{array}{l}\text { The lowest hierarchy level; A collection of measurable stability data } \\
\text { expressed in units }\end{array}$ \\
Attribute & $\begin{array}{l}\text { The middle hierarchy level; A collection of metrics which belongs to a } \\
\text { class of stability measures } \\
\text { The highest hierarchy level; A collection of attributes for measuring the } \\
\text { stability of handheld application usage }\end{array}$ \\
Criterion
\end{tabular}

A total number of eleven stability measures, with a number of eight stability metrics and three stability attributes, were outlined as having associated towards measuring the stability of handheld application usage. The definition of each stability measure is as depicted below (Table 2).

Table 2. Stability measures and descriptions

\begin{tabular}{|l|l|}
\hline Measure & Description \\
\hline Information Speed & Capability in handling information per time \\
Lateral Position $^{*}$ & Capability in positioning objects per time \\
Optimal Solution & Capability in solving tasks per time \\
\hline Data Entered & Errors Corrected \\
Focuses Distracted $^{* *}$ & The number of data entered per time \\
Lines Read $^{* *}$ & The number of errors corrected per time \\
Links Explored $^{* *}$ & The number of focuses distracted per time \\
Paths Traversed & The number of lines read per time \\
Steps Navigated & The number of links explored per time \\
Targets Located $^{* * *}$ & The number of paths traversed per time \\
\hline
\end{tabular}

Legend of the table:

* attribute determines the criterion (i.e. stability of handheld application usage)

*** metric determines the attribute

Data collected from the questionnaire is entered in the Statistical Package for the Social Sciences (SPSS) for the analysis process as well as to classify the stability measures into the hierarchical structure of metrics, attributes and criterion. This brings together two parts of evaluation tests: Pearson's Chi-square test and the Spearman's Rho test. Pearson's Chi-Square test was conducted to measure the amount of association between two different stability measures in two different 
hierarchy levels and the Spearman's Rho test was conducted to comprehend the relationship strength between two different stability measures in two different hierarchy levels.

The model for measuring the stability of handheld application usage is specifically developed using a conceptual framework, namely Stableness Measurement Framework (SMF) (Figure 1). This framework brings together different stability measures in different hierarchy levels. As illustrated below, the metric determines the attribute and the attribute determines the criterion (i.e. stability as criterion). Each level represents interaction with other level and the impact to one another to measure the stability of the desired handheld application usage. This can be explained as either none, one or more metrics to represent a single attribute.

The combination of these metrics could be represented as the components that contributed to only one attribute. And finally, these attributes are used to support in the calculation of the criterion that can be concluded as directly affected the stability of handheld application usage. This is the case at every level in which could be represented as an $\mathrm{M}-1$ relationship. For example, metric $\mathrm{M}_{1}$ $\ldots \mathrm{M}_{\mathrm{n}}$ are the input to attribute $\mathrm{A}_{\mathrm{A}}$ and criterion $\mathrm{C}_{\mathrm{C}}$ is an output for the attribute $\mathrm{A}_{\mathrm{A}}$. Consider if the value of metric $M_{1}, M_{2}, \ldots, M_{n-1}$ or $M_{n}$ increases so as the value of attribute $A_{A}$ and criterion $C_{C}$. Again, if the value of metric $M_{1}, M_{2}, \ldots, M_{n-1}$ or $M_{n}$ decreases so as the value of attribute $A_{A}$ and criterion $\mathrm{C}_{\mathrm{C}}$.

\section{RESULTS AND DISCUSSIONS}

\subsection{Results of Association Test}

Result of association test reported that metrics of Data Entered $(\mathrm{M}=4.52, \mathrm{SD}=.738)$, Errors Corrected $(\mathrm{M}=4.10, \mathrm{SD}=.979)$ and Focuses Distracted $(\mathrm{M}=3.65, \mathrm{SD}=1.027)$ were contributed towards measuring the stability of handheld application usage with $\mathrm{p}<.001$. Results also showed that metrics of Links Explored $(\mathrm{M}=4.25, \mathrm{SD}=.780)$, Lines Read $(\mathrm{M}=4.08, \mathrm{SD}=$ $.992)$ and Paths Traversed $(\mathrm{M}=3.95, \mathrm{SD}=.912)$ were contributed towards attribute Optimal Solution with $\mathrm{p}<.001$. Meanwhile, metrics of Steps Navigated $(\mathrm{M}=4.04, \mathrm{SD}=.905)$ and Targets Located $(\mathrm{M}=3.69, \mathrm{SD}=1.038)$ were also found contributed towards measuring the stability of handheld application usage with $\mathrm{p}<.001$.
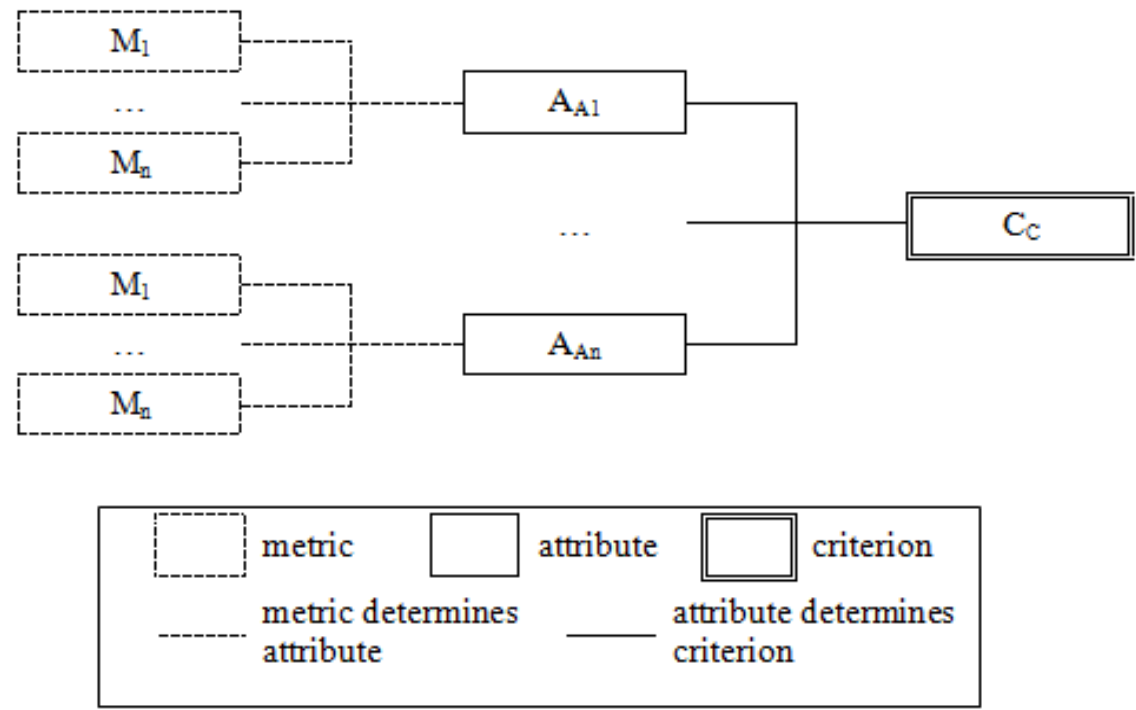

Figure 1. Stableness Measurement Framework (SMF) 
International Journal of Software Engineering \& Applications (IJSEA), Vol.4, No.5, September 2013

Finally, result of the association test also stated that the attributes of Information Speed $(\mathrm{M}=$ $4.34, \mathrm{SD}=.811)$, Lateral Position $(\mathrm{M}=4.27, \mathrm{SD}=.734)$ and Optimal Solution $(\mathrm{M}=4.27, \mathrm{SD}=$ .806) were found contributed towards measuring the stability of handheld application usage, with $\mathrm{p}<.001$. As a result, a total number of eleven stability measures (i.e. eight stability metrics and three stability attributes) were identified having associated and contributed towards measuring the stability of handheld application usage (Table 3).

Table 3. Result of association test

\begin{tabular}{|l|c|}
\hline \multicolumn{1}{c|}{ Stability Measures } & Mean \\
\hline Stability Attributes & \\
Information Speed & 4.34 \\
Lateral Position & 4.27 \\
Optimal Solution & 4.27 \\
\hline Stability Metrics & \\
Data Entered & 4.52 \\
Errors Corrected & 4.10 \\
Focuses Distracted & 3.65 \\
Lines Read Speed & 4.08 \\
Links Explored & 4.25 \\
Paths Traversed & 3.95 \\
Steps Navigated & 4.04 \\
Targets Located & 3.69 \\
\hline
\end{tabular}

Results from the association test were further ranked to prioritize the level of importance of each stability measure towards measuring the overall stability of handheld application usage (Table 4).

Table 4. Rank of stability measures

\begin{tabular}{|l|c|}
\hline \multicolumn{1}{|c|}{ Stability Measures } & Rank \\
\hline Stability Attributes & \\
Information Speed & 1 \\
Lateral Position & 2 \\
Optimal Solution & 3 \\
\hline Stability Metrics & \\
Data Entered & 1 \\
Links Explored & 2 \\
Errors Corrected & 3 \\
Lines Read & 4 \\
Steps Navigated & 5 \\
Paths Traversed & 6 \\
Targets Located & 7 \\
Focuses Distracted & 8 \\
\hline
\end{tabular}

\subsection{Results of Relationship Test}

Result of the relationship test revealed that there was a moderate and positive linear relationship between metrics Data Entered $(\mathrm{R}=.346)$, Errors Corrected $(\mathrm{R}=.251)$ and Lines Read $(\mathrm{R}=.298)$ towards attribute Information Speed with $\mathrm{p}<.001$. Results also found that the coefficient value of metrics Targets Located $(\mathrm{R}=.528)$ and Focuses Distracted $(\mathrm{R}=.470)$ were moderate and positive linear relationship towards attribute Lateral Position with $\mathrm{p}<.001$. Metrics Links 
Explored $(\mathrm{R}=.333)$, Steps Navigated $(\mathrm{R}=.385)$ and Paths Traversed $(\mathrm{R}=.410)$ were also reported to have a moderate and positive linear relationship between attribute Optimal Solution with $\mathrm{p}<.001$.

Finally, the relationship test also indicated the correlation strength between attributes Information Speed $(\mathrm{R}=.306)$, Lateral Position $(\mathrm{R}=.311)$ and Optimal Solution $(\mathrm{R}=.298)$ resulted having a moderate and positive linear relationship towards measuring the stability of handheld application usage with $\mathrm{p}<.001$. Based on the result of the relationship test, out of the total number of eleven stability measures, seven (i.e. five stability metrics and two stability attributes) were identified having moderate and positive linear relationship, three (i.e. two stability metrics and one stability attributes) were identified having low and positive linear relationship, while only one stability matric reported having high and positive linear relationship towards measuring the stability of handheld application usage (Table 5).

Table 5. Result of relationship test

\begin{tabular}{|l|l|}
\hline \multicolumn{1}{|c|}{ Stability Measures } & Relationship \\
\hline Attributes contributed towards criterion (attribute $\rightarrow$ criterion) & \\
Information Speed $\rightarrow$ Stability & Moderate, Positive \\
Lateral Position $\rightarrow$ Stability & Moderate, Positive \\
Optimal Solution $\rightarrow$ Stability & Low, Positive \\
\hline Metrics contributed towards attribute (metric $\rightarrow$ attribute) & \\
Data Entered $\rightarrow$ Information Speed & Moderate, Positive \\
Links Explored $\rightarrow$ Optimal Solution & Moderate, Positive \\
Errors Corrected $\rightarrow$ Information Speed & Low, Positive \\
Lines Read $\rightarrow$ Information Speed & Low, Positive \\
Steps Navigated $\rightarrow$ Optimal Solution & Moderate, Positive \\
Paths Traversed $\rightarrow$ Optimal Solution & Moderate, Positive \\
Targets Located $\rightarrow$ Lateral Position & High, Positive \\
Focuses Distracted $\rightarrow$ Lateral Position & Moderate, Positive \\
\hline
\end{tabular}

Legend of the table: Correlation is significant at the 0.001 level (2-tailed) and range in the value of +1 to -1

Results from the relationship test were further analysed to obtain the value of weightage of each stability measure towards measuring the overall stability of handheld application usage (Table 6). 
International Journal of Software Engineering \& Applications (IJSEA), Vol.4, No.5, September 2013

Table 6. Weight of stability measures

\begin{tabular}{|l|c|}
\hline \multicolumn{1}{|c|}{ Stability Measures } & Weight \\
\hline Attributes contributed towards criterion (attribute $\rightarrow$ criterion) & \\
Information Speed $\rightarrow$ Stability & .306 \\
Lateral Position $\rightarrow$ Stability & .311 \\
Optimal Solution $\rightarrow$ Stability & .298 \\
\hline Metrics contributed towards attribute (metric $\rightarrow$ attribute) & .346 \\
Data Entered $\rightarrow$ Information Speed & .251 \\
Errors Corrected $\rightarrow$ Information Speed & .298 \\
Lines Read $\rightarrow$ Information Speed & .528 \\
Targets Located $\rightarrow$ Lateral Position & .470 \\
Focuses Distracted $\rightarrow$ Lateral Position & .333 \\
Links Explored $\rightarrow$ Optimal Solution & .385 \\
Steps Navigated $\rightarrow$ Optimal Solution & .410 \\
Paths Traversed $\rightarrow$ Optimal Solution & \\
\hline
\end{tabular}

The findings derived from the analysis of both association test and relationship test produced lists of codes to represent each stability metric and attribute, presented as $\mathrm{M}_{\mathrm{m}} \bullet \mathrm{A}_{\mathrm{a}} \bullet \mathrm{C}_{\text {STB }}$ and $\mathrm{A}_{\mathrm{a}} \bullet \mathrm{C}_{\text {STB }}$ respectively (Table 7). Symbolized as $\mathrm{M}_{\mathrm{m}}, \mathrm{M}$ represents the stability metrics while ${ }_{\mathrm{m}}$ represents the sequential series ( $\mathrm{m}$-th) of the stability metric such as $1,2, \ldots, \mathrm{m}$. Similarly, symbolized as $\mathrm{A}_{\mathrm{a}}$, A represents the stability attribute while ${ }_{\mathrm{a}}$ represents the sequential series (a-th) of the stability attribute such as $1,2, \ldots$, a. Finally, symbolized as $\mathrm{C}_{\mathrm{STB}}, \mathrm{C}$ represents the stability criterion in which ${ }_{\text {STB }}$ represents the abbreviation of the stability.

Table 7. Code of stability measures

\begin{tabular}{|l|c|}
\hline \multicolumn{1}{|c|}{ Stability Measures } & Code \\
\hline Attributes contributed towards criterion (attribute $\rightarrow$ criterion) & $\mathrm{A}_{\mathrm{a}} \bullet \mathrm{C}_{\mathrm{STB}}$ \\
Information Speed $\rightarrow$ Stability & $\mathrm{A}_{1} \bullet \mathrm{C}_{\mathrm{STB}}$ \\
Lateral Position $\rightarrow$ Stability & $\mathrm{A}_{2} \bullet \mathrm{C}_{\mathrm{STB}}$ \\
Optimal Solution $\rightarrow$ Stability & $\mathrm{A}_{3} \bullet \mathrm{C}_{\mathrm{STB}}$ \\
\hline Metrics contributed towards attributes (metrics $\rightarrow$ attributes) & $\mathrm{M}_{\mathrm{m}} \bullet \mathrm{A}_{\mathrm{a}} \bullet \mathrm{C}_{\mathrm{STB}}$ \\
Data Entered $\rightarrow$ Information Speed & $\mathrm{M}_{1} \bullet \mathrm{A}_{1} \bullet \mathrm{C}_{\mathrm{STB}}$ \\
Errors Corrected $\rightarrow$ Information Speed & $\mathrm{M}_{2} \bullet \mathrm{A}_{1} \bullet \mathrm{C}_{\mathrm{STB}}$ \\
Lines Read $\rightarrow$ Information Speed & $\mathrm{M}_{3} \bullet \mathrm{A}_{1} \bullet \mathrm{C}_{\mathrm{STB}}$ \\
Targets Located $\rightarrow$ Lateral Position & $\mathrm{M}_{1} \bullet \mathrm{A}_{2} \bullet \mathrm{C}_{\mathrm{STB}}$ \\
Focuses Distracted $\rightarrow$ Lateral Position & $\mathrm{M}_{2} \bullet \mathrm{A}_{2} \bullet \mathrm{C}_{\mathrm{STB}}$ \\
Links Explored $\rightarrow$ Optimal Solution & $\mathrm{M}_{1} \bullet \mathrm{A}_{3} \bullet \mathrm{C}_{\mathrm{STB}}$ \\
Steps Navigated $\rightarrow$ Optimal Solution & $\mathrm{M}_{2} \bullet \mathrm{A}_{3} \bullet \mathrm{C}_{\mathrm{STB}}$ \\
Paths Traversed $\rightarrow$ Optimal Solution & $\mathrm{M}_{3} \bullet \mathrm{A}_{3} \bullet \mathrm{C}_{\mathrm{STB}}$ \\
\hline
\end{tabular}

Furthermore, findings derived from the analysis of both association test and relationship test also produced lists of codes to represent the weight of each stability metric and attribute, presented as $\omega_{\mathrm{ATTm}}$ and $\omega_{\mathrm{CRTa}}$ respectively (Table 8 ). $\omega$ represents the symbol of weights, meanwhile symbolized as ATTm, $m$ represents the sequential series (m-th) of the stability metric such as 1,2 , $\ldots, \mathrm{m}$ that contributed towards particular attribute, ${ }_{\mathrm{ATT}}$, and finally symbolized as ${ }_{\mathrm{CRTa}}{ }_{\mathrm{a}}$ represents the sequential series (a-th) of the stability attribute such as $1,2, \ldots$, a that contributed towards measuring the stability of handheld application usage, in which ${ }_{\mathrm{CRT}}$ represents the abbreviation of the stability, coded as STB. 
International Journal of Software Engineering \& Applications (IJSEA), Vol.4, No.5, September 2013

Table 8 . Weight code of stability measures

\begin{tabular}{|l|c|}
\hline \multicolumn{1}{|c|}{ Stability Measures } & Code \\
\hline Attributes contributed towards criterion (attribute $\rightarrow$ criterion) & $\omega_{\text {CRTa }}$ \\
Information Speed $\rightarrow$ Stability & $\omega_{\text {STB1 }}$ \\
Lateral Position $\rightarrow$ Stability & $\omega_{\text {STB2 }}$ \\
Optimal Solution $\rightarrow$ Stability & $\omega_{\text {STB } 3}$ \\
\hline Metrics contributed towards attributes (metrics $\rightarrow$ attributes) & $\omega_{\text {ATTm }}$ \\
Data Entered $\rightarrow$ Information Speed & $\omega_{\text {IS1 }}$ \\
Errors Corrected $\rightarrow$ Information Speed & $\omega_{\text {IS2 }}$ \\
Lines Read $\rightarrow$ Information Speed & $\omega_{\text {IS3 }}$ \\
Targets Located $\rightarrow$ Lateral Position & $\omega_{\text {LP1 }}$ \\
Focuses Distracted $\rightarrow$ Lateral Position & $\omega_{\text {LP2 }}$ \\
Links Explored $\rightarrow$ Optimal Solution & $\omega_{\text {OS1 }}$ \\
Steps Navigated $\rightarrow$ Optimal Solution & $\omega_{\text {OS2 }}$ \\
Paths Traversed $\rightarrow$ Optimal Solution & $\omega_{\text {OS3 }}$ \\
\hline
\end{tabular}

\section{Steadiness Measurement Model}

The analysis of association and relationship tests results the development of a model for measuring the stability of handheld applications usage, namely Stableness Measurement Model (SMM) (Figure 2).

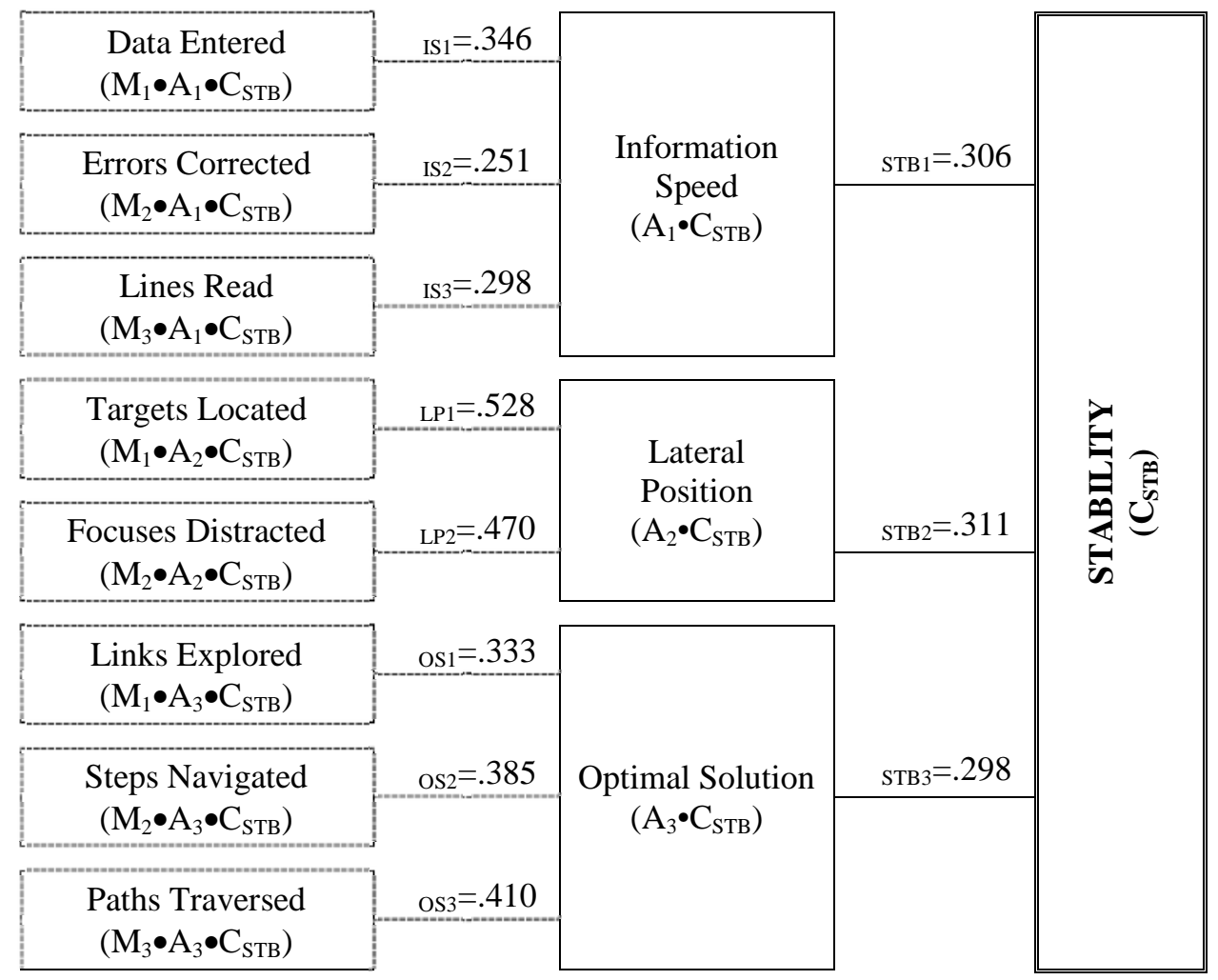

Figure 2. Stableness Measurement Model (SMM) 


\subsection{Measuring the Metrics}

In order to measure the stability of handheld application usage, score for each metric can be formulated and calculated generally as the proportion of the difference between number of expected and actual activities occurred per time out of the total number of estimated activities occurred per time. Hence can be represented as

$$
\underset{\left(\mathrm{M}_{1 \ldots \mathrm{m}} \cdot \mathrm{A}_{1 \ldots \mathrm{a}} \cdot \mathrm{C}_{\mathrm{STB}}\right)}{\operatorname{Stability} \text { Metric }}=\frac{\begin{array}{c}
\text { Number of actual activities occurred per time }- \text { Number } \\
\text { of expected activities occurred per time }
\end{array}}{\text { Total number of expected activities occurred }}
$$

Detail representation for measuring stability metrics Data Entered $\left(\mathrm{M}_{1} \bullet \mathrm{A}_{1} \bullet \mathrm{C}_{\mathrm{STB}}\right)$, Errors Corrected $\left(\mathrm{M}_{2} \bullet \mathrm{A}_{1} \bullet \mathrm{C}_{\mathrm{STB}}\right)$ and Lines Read $\left(\mathrm{M}_{3} \bullet \mathrm{A}_{1} \bullet \mathrm{C}_{\mathrm{STB}}\right)$ that contribute towards attribute Information Speed $\left(\mathrm{A}_{1} \bullet \mathrm{C}_{\mathrm{STB}}\right)$, thus can be referred as

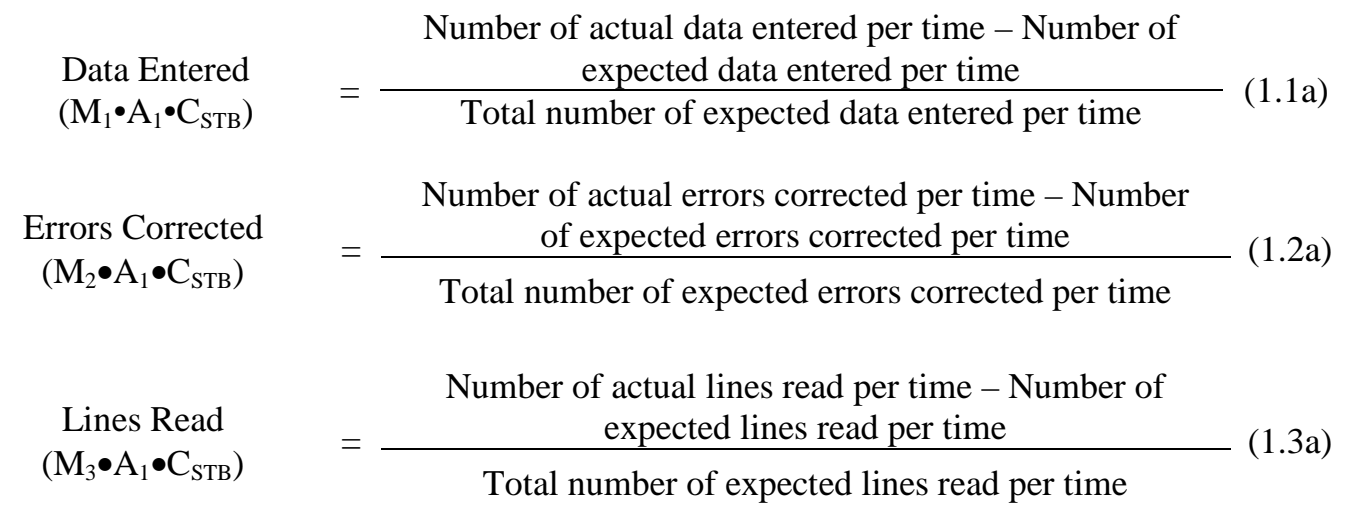

Detail representation for measuring stability metrics Targets Located $\left(\mathrm{M}_{1} \bullet \mathrm{A}_{2} \bullet \mathrm{C}_{\mathrm{STB}}\right)$ and Focuses Distracted $\left(\mathrm{M}_{2} \bullet \mathrm{A}_{2} \bullet \mathrm{C}_{\mathrm{STB}}\right)$ that contribute towards attribute Lateral Position $\left(\mathrm{A}_{2} \bullet \mathrm{C}_{\mathrm{STB}}\right)$, thus can be referred as

$$
\begin{aligned}
& \begin{array}{c}
\text { Targets Located } \\
\left(\mathrm{M}_{1} \bullet \mathrm{A}_{2} \bullet \mathrm{C}_{\text {STB }}\right)
\end{array}=\frac{\begin{array}{c}
\text { Number of actual targets located per time }- \text { Number of } \\
\text { expected targets located per time }
\end{array}}{\text { Total number of expected targets located per time }}
\end{aligned}
$$

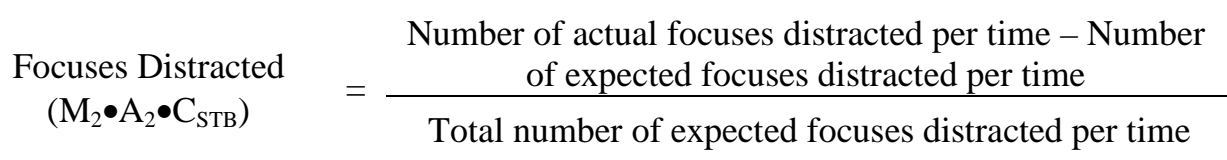

Detail representation for measuring stability metrics Links Explored $\left(\mathrm{M}_{1} \bullet \mathrm{A}_{3} \bullet \mathrm{C}_{\mathrm{STB}}\right)$, Steps Navigated $\left(\mathrm{M}_{2} \bullet \mathrm{A}_{3} \bullet \mathrm{C}_{\text {Sтв }}\right)$ and Paths Traversed $\left(\mathrm{M}_{3} \bullet \mathrm{A}_{3} \bullet \mathrm{C}_{\text {STB }}\right)$ that contribute towards attribute Optimal Solution $\left(\mathrm{A}_{3} \cdot \mathrm{C}_{\mathrm{STB}}\right)$, thus can be referred as

$$
\begin{gathered}
\text { Links Explored } \\
\left(\mathrm{M}_{1} \bullet \mathrm{A}_{3} \bullet \mathrm{C}_{\text {STB }}\right)
\end{gathered}=\frac{\begin{array}{c}
\text { Number of actual links explored per time }- \text { Number of } \\
\text { expected links explored per time }
\end{array}}{\text { Total number of expected links explored per time }}
$$




$\begin{gathered}\begin{array}{c}\text { Steps Navigated } \\ \left(\mathrm{M}_{2} \bullet \mathrm{A}_{3} \bullet \mathrm{C}_{\mathrm{STB}}\right)\end{array} \\ \begin{array}{c}\text { Paths Traversed } \\ \left(\mathrm{M}_{3} \bullet \mathrm{A}_{3} \bullet \mathrm{C}_{\mathrm{STB}}\right)\end{array}\end{gathered} \quad=\frac{\begin{array}{c}\text { Number of actual steps navigated per time }- \text { Number of } \\ \text { expected steps navigated per time }\end{array}}{\text { Total number of expected steps navigated per time }}(1.2 \mathrm{c})$

\subsection{Measuring the Attributes}

Score for each stability attribute can be formulated and calculated generally as the proportion of the accumulated product of attribute weight and the metric value out of the total of accumulated weight for each stability attribute. Hence can be represented as

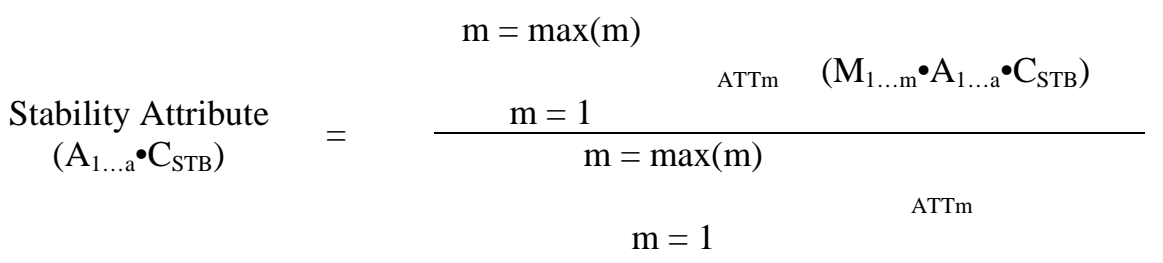

which can be further expanded as

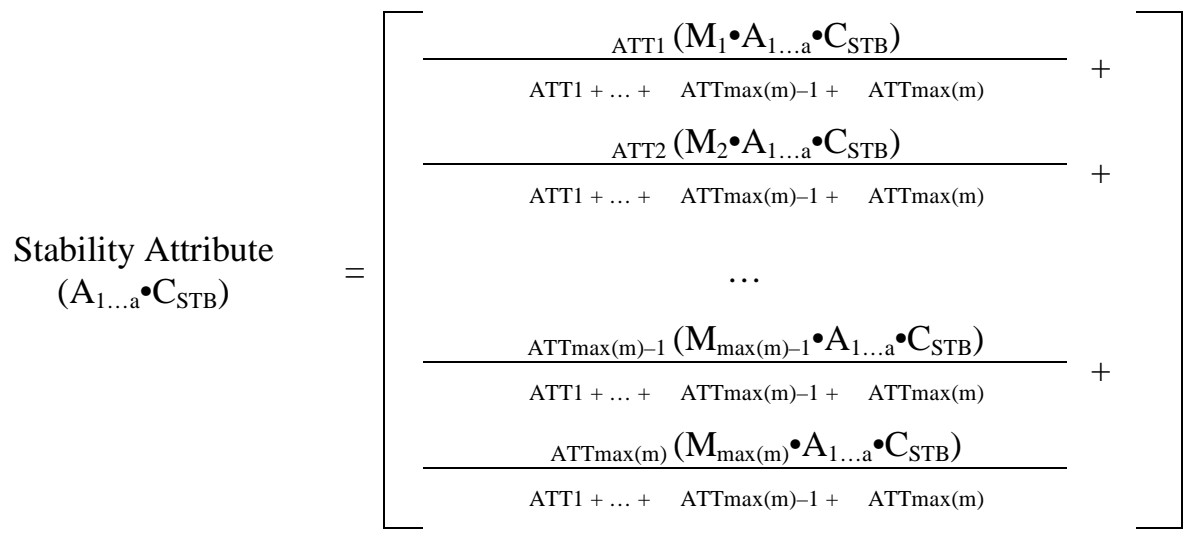

Detail representations for measuring stability attribute Information Speed $\left(\mathrm{A}_{1} \cdot \mathrm{C}_{\mathrm{STB}}\right)$ that contribute towards measuring the stability of handheld application usage can be referred as

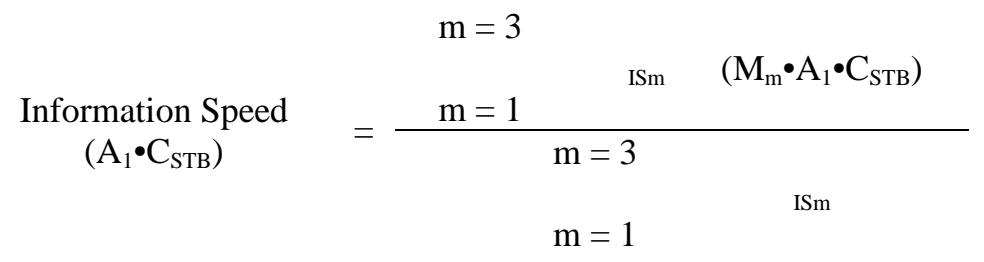

hence can be further expanded as 


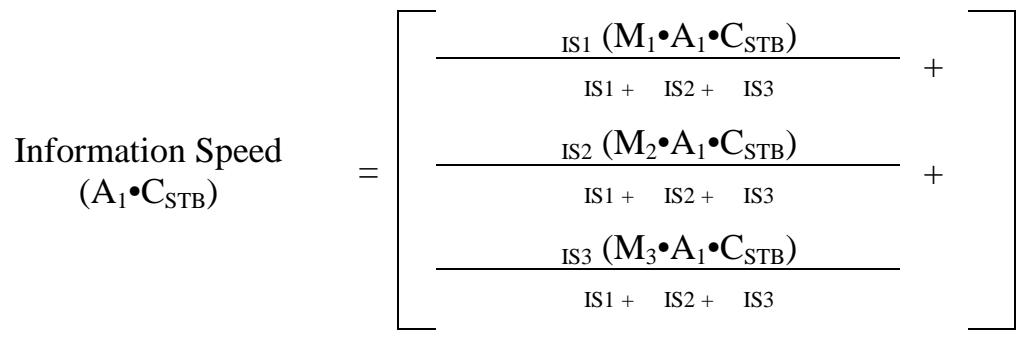

which involved the proportion of the accumulated product of weight and value of each stability metrics Data Entered $\left(\omega_{\mathrm{IS} 1}[=.346] \times \mathrm{M}_{1} \bullet \mathrm{A}_{1} \bullet \mathrm{C}_{\mathrm{STB}}\right)$, Errors Corrected $\left(\omega_{\mathrm{IS} 2}[=.251] \times \mathrm{M}_{2} \bullet \mathrm{A}_{1} \bullet \mathrm{C}_{\mathrm{STB}}\right)$ and Lines Read $\left(\omega_{\mathrm{IS} 3}[=.298] \times \mathrm{M}_{3} \bullet \mathrm{A}_{1} \bullet \mathrm{C}_{\text {Ств }}\right)$ that contribute towards attribute Information Speed $\left(\mathrm{A}_{1} \cdot \mathrm{C}_{\mathrm{STB}}\right)$ divide by the total of attribute weights $\left(\omega_{\mathrm{IS} 1}+\omega_{\mathrm{IS} 2}+\omega_{\mathrm{IS} 3}=.346+.251+.298=0.895\right)$.

Detail representations for measuring stability attribute Lateral Position $\left(\mathrm{A}_{2} \bullet \mathrm{C}_{\text {STB }}\right)$ that contribute towards measuring the stability of handheld application usage can be referred as

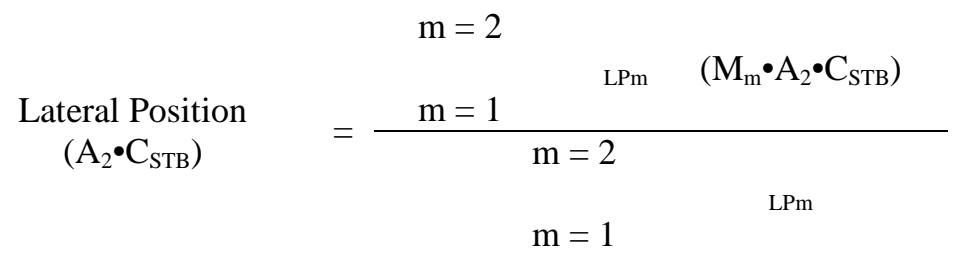

hence can be further expanded as

$$
\begin{gathered}
\text { Lateral Position } \\
\left(\mathrm{A}_{2} \bullet \mathrm{C}_{\mathrm{STB}}\right)
\end{gathered}=\left[\begin{array}{c}
\frac{\omega_{\mathrm{LP} 1}\left(\mathrm{M}_{1} \bullet \mathrm{A}_{2} \cdot \mathrm{C}_{\mathrm{STB}}\right)}{\omega_{\mathrm{LP} 1}+\omega_{\mathrm{LP} 2}} \\
\frac{\omega_{\mathrm{LP} 2}\left(\mathrm{M}_{2} \bullet \mathrm{A}_{2} \cdot \mathrm{C}_{\mathrm{STB}}\right)}{\omega_{\mathrm{LP} 1}+\omega_{\mathrm{LP} 2}}
\end{array}\right]
$$

which involved the proportion of the accumulated product of weight and value of each stability metrics Targets Located $\left(\omega_{\mathrm{LP} 1}[=.528] \times \mathrm{M}_{1} \bullet \mathrm{A}_{2} \bullet \mathrm{C}_{\mathrm{STB}}\right)$ and Focuses Distracted $\left(\omega_{\mathrm{LP} 2}[=.470] \mathrm{x}\right.$ $\left.\mathrm{M}_{2} \bullet \mathrm{A}_{2} \bullet \mathrm{C}_{\text {STB }}\right)$ that contribute towards attribute Lateral Position $\left(\mathrm{A}_{2} \bullet \mathrm{C}_{\mathrm{STB}}\right)$ divide by the total of attribute weights $\left(\omega_{\mathrm{LP} 1}+\omega_{\mathrm{LP} 2}=.528+.470=0.998\right)$.

Detail representations for measuring stability attribute Optimal Solution $\left(\mathrm{A}_{3} \cdot \mathrm{C}_{\mathrm{STB}}\right)$ that contribute towards measuring the stability of handheld application usage can be referred as

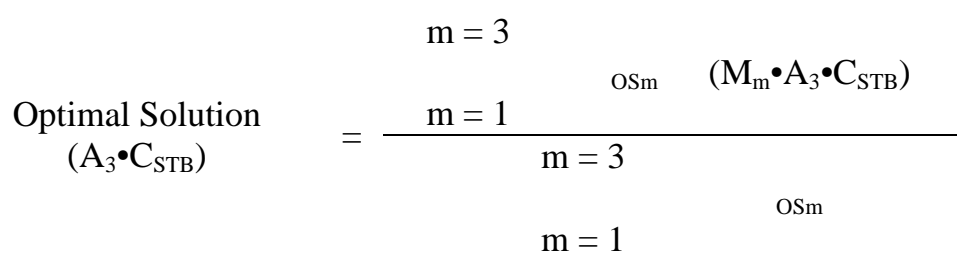

hence can be further expanded as

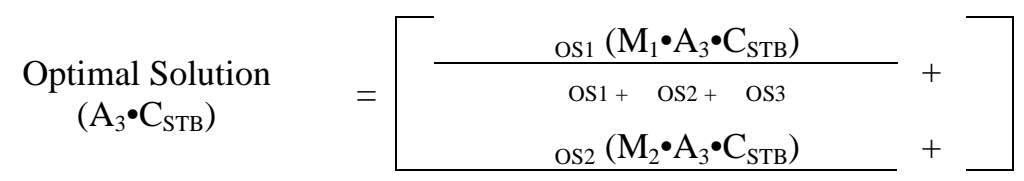




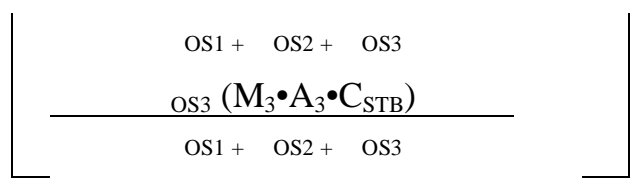

which involved the proportion of the accumulated product of weight and value of each stability metrics Links Explored ( $\left.\omega_{\mathrm{OS} 1}[=.333] \quad \mathrm{x} \quad \mathrm{M}_{1} \bullet \mathrm{A}_{3} \bullet \mathrm{C}_{\mathrm{STB}}\right)$, Steps Navigated ( $\omega_{\mathrm{OS} 2}[=.385] \mathrm{x}$ $\left.\mathrm{M}_{2} \bullet \mathrm{A}_{3} \bullet \mathrm{C}_{\mathrm{STB}}\right)$ and Paths Traversed ( $\left.\omega_{\mathrm{OS} 3}[=.410] \quad \mathrm{x} \mathrm{M}_{3} \bullet \mathrm{A}_{3} \bullet \mathrm{C}_{\mathrm{STB}}\right)$ that contribute towards attribute Optimal Solution $\left(\mathrm{A}_{3} \cdot \mathrm{C}_{\mathrm{STB}}\right)$ divide by the total of attribute weights $\left(\omega_{\mathrm{OS} 1}+\omega_{\mathrm{OS} 2}+\omega_{\mathrm{OS} 3}=.333+\right.$ $.385+.410=1.128$ ).

\subsection{Measuring the Criterion}

Score for Stability $\left(\mathrm{C}_{\mathrm{STB}}\right)$ can be formulated and calculated generally as the proportion of the accumulated product of criterion weight and the attribute value out of the total of accumulated weights for each stability criterion. Hence can be represented as

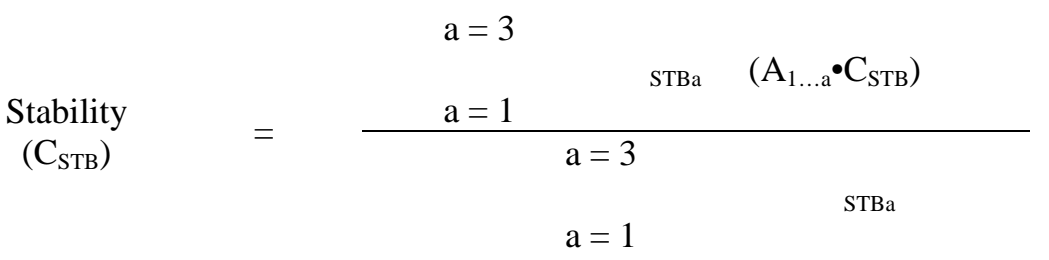

which can be further expanded as

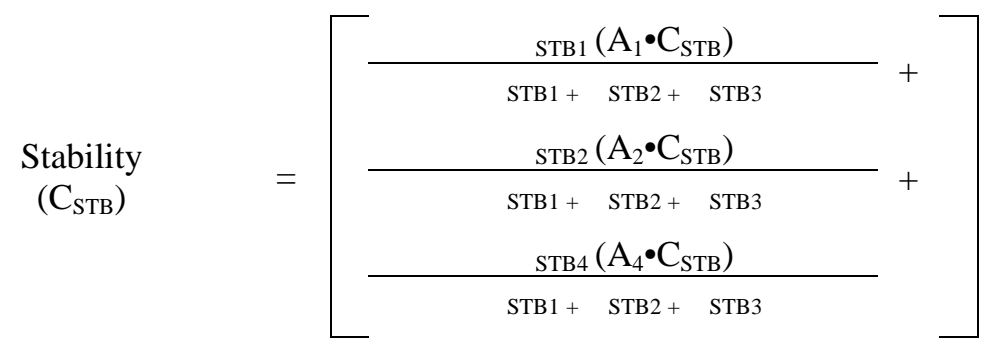

which involved the proportion of the accumulated product of weight and value of each stability attributes Information Speed $\left(\omega_{\text {STB } 1}[=.306] \times \mathrm{A}_{1} \bullet \mathrm{C}_{\mathrm{STB}}\right)$, Lateral Position $\left(\omega_{\mathrm{STB} 2}[=.311] \times \mathrm{A}_{2} \bullet \mathrm{C}_{\mathrm{STB}}\right)$ and Optimal Solution $\left(\omega_{\mathrm{STB} 3}[=.298] \times \mathrm{A}_{3} \bullet \mathrm{C}_{\mathrm{STB}}\right)$ that contribute towards measuring the stability of handheld application $\left(\mathrm{C}_{\mathrm{ACC}}\right)$ divide by the total of criterion weights $\left(\omega_{\mathrm{STB} 1}+\omega_{\mathrm{STB} 2}+\omega_{\mathrm{STB} 3}=.306+\right.$ $.311+.298=0.915)$.

Score for Stability $\left(\mathrm{C}_{\mathrm{STB}}\right)$ can be further analysed according to five distinct classifications as described below (Table 9). Prioritizing the stability of handheld application usage can be done by converting the values into words or sentences with which evaluators from various backgrounds and understanding can interpret the information accurately and comprehensively. 
Table 9. Prioritizing stability level

\begin{tabular}{|c|c|l|}
\hline Level & Score $\left(\mathrm{C}_{\mathrm{STB}}\right)$ & \multicolumn{1}{c|}{ Description } \\
\hline 1 & $0.000 \leq \mathrm{C}_{\mathrm{STB}}<0.200$ & $\begin{array}{l}\text { Most badly absence or shortage of a desirable usage } \\
\text { quality that attains stability level of unable to perform } \\
\text { comprehensively } \\
2\end{array}$ \\
3 & $0.200 \leq \mathrm{C}_{\mathrm{STB}}<0.400 \leq \mathrm{C}_{\mathrm{STB}}<0.600$ & $\begin{array}{l}\text { Lack of a desirable usage quality that attains stability } \\
\text { level of the least excellent } \\
\text { Average of a desirable usage quality that can be tolerable } \\
\text { to consider good enough } \\
\text { Complete the specific requirements of a desirable usage } \\
\text { quality that achieves stability level of almost in a state of } \\
\text { being practical } \\
\text { Fulfil all the requirements of a desirable usage quality that } \\
\text { achieves stability level of very high distinction of } \\
\text { proficiency }\end{array}$ \\
\hline
\end{tabular}

\section{CONCLUSIONS}

The model developed not only reveals the stability between handheld users and its application but also provide a better understanding on the relationship of these factors. In addition, this model can be established as a concrete evaluation technique for measuring the stability of handheld application usage. For the future, it is recommended to evaluate cases between the stability model and the actual handheld applications. With extensive experiences, stability measures might change and additional new criteria could be included in the future work. Therefore, the model developed need to be refined practically through many applications in the real work environment.

\section{REFERENCES}

[1] Fayad, M. E. \& Altman, A., (2001) "An introduction to software stability: Studying the design and development that produces stable (or unstable) software", Communications of the ACM, Vol. 44, No. 9 , pp $95-98$.

[2] ISO/IEC 9126, (2004) "Software engineering - Product quality. Part 1: 2001 - Parts 2 to 4", International Organization for Standardization, Geneva.

[3] Hina, M. D., (2012) "Quality attribute - Driven software architecture of a pervasive multimodal computing system', AMAIUB - CCS Research Journal, Vol. 2, No. 1.

[4] Sharma A. K., Kalia, A. \& Singh, H., (2012) "The software quality assurance framework for CBSD", International Journal of Advanced Research in Computer Science and Software Engineering, Vol. 2, No. 11, pp $161-170$.

[5] Khaled, O. M. \& Hosny, H. M., (2008) "A quality attribute-based approach for applying performance design patterns", International Journal of Software Engineering, Vol. 1, No. 1, pp 101 - 131.

[6] Hassenzahl, M., (2004) "The interplay of beauty, goodness, and usability in interactive products", Human-Computer Interaction, Vol. 19, No. 4, pp 319 - 349.

[7] Min, W., Jie, L., Hong, J., Ning, L., Wenzhao, W. \& Zhenjie, H., (2011) "Evaluation on influence factor of mechanism usability based on analytical prey incidence process", Proceedings of the 2011 International Conference on Consumer Electronics, Communications and Networks (CECNet), pp $2200-2203$.

[8] Pan, W., (2011) "Quantifying the stability of software systems via simulation in dependency networks", World Academy of Science, Engineering and Technology, Vol. 60, pp 1513 - 1520.

[9] Tuch, A., Roth, S., Hornbæk, K., Opwisa, K., \& Bargas-Avilaa, J., (2012) "Is beautiful really usable? Toward understanding the relation between usability, aesthetics, and affect in HCI", Computers in Human Behavior, Vol. 28, No. 5, pp 1596 - 1607. 
[10] Li, Z. \& Bai, X., (2010) "Influences of perceived risk and system usability on the adoption of mobile banking service", Proceedings of the Third International Symposium on Computer Science and Computational Technology (ISCSCT), pp $51-54$.

[11] Yang, P., Qin, G., Yan, Y., Wang, H. \& Zhang, L., (2011) "On the channel usability of wireless mesh networks: When stability plays with you", International Journal of Ad Hoc and Ubiquitous Computing, Vol. 8, No. 1/2, pp $64-77$.

[12] Nicolau, H. \& Jorge, J., (2012) "Touch typing using thumbs: Understanding the effect of mobility and hand posture", Proceedings of the 2012 ACM Annual Conference on Human Factors in Computing Systems (CHI 2012), New York, USA, ACM, pp 2683 - 2686.

[13] Oliveira, R., Cherubini, M. \& Oliver, N., (2012) "Influence of usability on customer satisfaction: A case study on mobile phone services", Proceedings of the I-UxSED CEUR Workshop, pp 14 - 19.

\section{Authors}

Thirteen years of extensive experience in teaching and mentoring graduate students at public and private higher education institutions and eleven years of comprehensive experience in research and development specifically on handheld - based software application systems with interest on the field of Software Engineering, specializing on software quality, software certification, software management and human computer interaction.

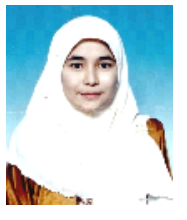

